\title{
Ethical expertise revisited
}

\author{
Bert Gordijn · Wim Dekkers
}

Published online: 10 June 2008

(C) The Author(s) 2008

The status of knowledge, skills and virtues in morality has been discussed since the days of Socrates. However, in the last few decades, ethicists have become involved in healthcare, business, industry, journalism as never before. This development has triggered a modern debate about whether bestowing a specific authority in morals upon specialists is a good idea. The discussion focuses on the possibility, content, and desirability of ethical expertise and ethics experts. Some authors are very skeptical about the status of ethicists as professionals. They challenge the very concept of expertise in ethics because of the dissimilarity of moral knowledge and expert knowledge in other professions, such as medicine and engineering. Others are in favor of the concept of ethical expertise but argue that the ethics expert should exclusively focus on procedural and formal matters such as analysis and clarification of concepts and arguments. According to the strongest view the ethicist is considered an expert in substantively pointing out what is morally right or wrong. Jukka Varelius contributes to this debate in his paper "Is ethical expertise possible?" He carefully assesses and rejects the criticism raised against ethical expertise.

With her paper "Be careful what you wish for? Theoretical and ethical aspects of wish-fulfilling medicine" Alena Buyx won the second prize in the ESPMH essay contest for young scholars in 2007. She analyses theoretical aspects and ethical implications of the growing tendency towards wish-fulfilling medicine and concludes that it is hard to provide strong ethical arguments why wish-

B. Gordijn · W. Dekkers $(\bowtie)$

Department of Ethics, Philosophy and History of Medicine,

Radboud University Nijmegen Medical Centre, 137 EFG,

PO Box 9101, 6500 HB Nijmegen, The Netherlands

e-mail: w.dekkers@efg.umcn.nl fulfilling medicine should be banned or discouraged altogether. However, the numerous questions that surround wish-fulfilling medical procedures clearly mark them out as having a special status amongst other medical activities. Thus, more reflection about the subject, goal and ends of modern medicine is needed in order to reach any definite conclusion about the ethical assessment of the matter.

Carl-Åke Elmersjö and Gert Helgesson present and analyze the results of an empirical study concerning the notion of "just health care" amongst health care personnel on all organizational levels in three Swedish hospitals. They first lay bare what concept of justice is pivotal to the understanding of the personnel. Secondly, they try to find out how this understanding informs the way in which priorities are made in daily clinical practice.

The next two papers are cross-cultural or cross country comparative studies. Ralf Jox et al. compare legal approaches and ethico-legal discourse concerning substitute decision making in medicine in England and Germany. In their comparison, they highlight the following issue: (1) order of relatives who serve as health care proxies, (2) respective roles and decisional powers of patient-appointed versus court-appointed substitute decision-makers, and (3) legal criteria to guide substitute decision-makers. Next, Subrata Chattopadhyay and Alfred Simon demonstrate that culture significantly influences individuals' experience of life as well as their understanding of the moral meaning of illness, suffering and death. In their paper "East meets West: Cross-cultural perspective in end-of-life decision making from Indian and German viewpoints" the authors analyze differences in the roles of patient, family and physicians in dealing with endof-life decisions in India and Germany.

Bernward Gesang concentrates on end-of-life issues as well in his paper "Passive and active euthanasia: What is 
the difference?" Discussing and refining the theory developed by Dieter Birnbacher in his "Tun und Unterlassen" (1995), he defends a purely descriptive distinction between active and passive euthanasia.

The next two articles concentrate on ethical issues in research. The first paper, "The informed consent aftermath of the genetic revolution. An Italian example of implementation", is authored by Federica Artizzu. The author considers the development of biobanks and the associated problems of discrimination, stigmatization and psychological stress that might occur if data contained in these banks are being misused. Against this backdrop the paper takes up the role of informed consent in the context of genetic research. Artizzu demonstrates the need to develop an ethical framework tailored to the specific features of each genetic research project. As an example, the case of a private biotechnology company, SharDNA is presented. Its biobank was developed from a genetic research project carried out on isolated populations living on Sardinia. The paper highlights how the company is tackling the problem of informed consent and other ethical requirements for genetic research.

Lawrence Burns takes up the issue of dignity in research involving human subjects. He especially draws on Lennart Nordenfelt's thinking about dignity (2003, 2004). Moreover, he examines Canada's research ethics guidelines that consider dignity to be a foundational concept and the protection of the dignity of research subjects as a measure that prevents "the impoverishment of humanity as a whole". Finally, he sketches a functional model for attributing inherent dignity that avoids the untenable connotations of speciesism.

The last two papers focus on issues in philosophy of medicine. In "Sensibility and clinical understanding" Per Nortvedt makes a case for the significance of sensibility in shaping clinical knowledge and practice in medicine and health care. He regards the capacity of being distressed by the suffering of others as opening up for ethical responsibility as well as a presupposition for full-fledged clinical knowledge in medical care and health care. Urban Wiesing, finally, examines the work of Immanuel Kant and its influence on medicine. He first focuses on Kant's specific remarks on medicine and then examines the broader impact of his philosophy on the field over time.

Open Access This article is distributed under the terms of the Creative Commons Attribution Noncommercial License which permits any noncommercial use, distribution, and reproduction in any medium, provided the original author(s) and source are credited.

\section{References}

Birnbacher, D. 1995. Tun und Unterlassen. Stuttgart.

Nordenfelt, L. 2003. Dignity of the elderly: An introduction. Medicine, Health Care and Philosophy 6: 199-101.

Nordenfelt, L. 2004. The varieties of dignity. Health Care Analysis 12 (2): 69-81. 